\title{
Association between triglyceride glucose index and carotid atherosclerosis in patients with type 2 diabetes mellitus: a cross-sectional study
}

\author{
Hang Li \\ The Affiliated Hospital of Southwest Medical University https://orcid.org/0000-0001-8420-2870 \\ Jie Lin \\ The Affiliated Hospital of Southwest Medical University \\ Yi ying Liu \\ The Affiliated Hospital of Southwest Medical University \\ Yao Liu \\ The Affiliated Hospital of Southwest Medical University \\ Qin Wan ( $D$ wanqin0513@163.com ) \\ The Affiliated Hospital of Southwest Medical University https://orcid.org/0000-0002-9147-7538
}

\section{Research}

Keywords: Triglyceride glucose index, Carotid atherosclerosis, Type 2 diabetes mellitus, Insulin resistance

Posted Date: November 23rd, 2021

DOI: https://doi.org/10.21203/rs.3.rs-1078184/v1

License: () (i) This work is licensed under a Creative Commons Attribution 4.0 International License. Read Full License 


\section{Abstract \\ Background}

Carotid atherosclerosis (CAS) lacks a simple and relatively accurate predictor. Triglyceride glucose (TyG) index is a simple indicator of insulin resistance, but the association between TyG index and CAS in patients with type 2 diabetes mellitus (T2DM) is less certain. This study aimed to investigate whether TyG index can predict CAS onset effectively.

\section{Methods}

In total, 1476 T2DM patients were included in cross-sectional analysis. TyG index (calculated by In [fasting triglycerides (mg/dL) $\times$ fasting plasma glucose $(\mathrm{mg} / \mathrm{dL}) / 2]$ ) was split into tertiles (Tertile1-Tertile3). The main outcome was CAS prevalence as defined with carotid intima-media thickness (CIMT) $\geq 1.0 \mathrm{~mm}$ or carotid plaque. Logistic regression analysis was used to analyze the association between TyG index and CAS in patients with T2DM.

\section{Results}

In cross-sectional analysis, a total of $62.3 \%$ of T2DM patients had CAS, patients with a higher TyG index had a higher risk of CAS $\left(\chi^{2}=13.856, P<0.01\right)$. After confounder adjustment, patients with T2DM in the high tertile of TyG index had a greater risk to developing CAS than those in the low tertile $(O R=1.451,95 \% C l=1.107-1.902, P=0.007)$. Higher TyG index values were also associated with increased odds of CAS in patients with T2DM who were female, who were younger than 65 years old, who suffered from hypertension or obesity.

\section{Conclusion}

TyG index was significantly associated with CAS, suggesting that TyG index is a potential predictor for CAS in patients with T2DM.

\section{Introduction}

Carotid atherosclerosis (CAS) is now widely recognized as a multifactorial disease with outcomes that arise from complex factors such as plaque components, blood flow, and inflammation [1]. Furthermore, hyperglycemia and insulin resistance are key players in the development of CAS and its complications [2-4]. The proinflammatory state and perturbed insulin signaling of intimal cells, consistent with the presence of insulin resistance, may participate in atherosclerosis [3]. Both increased carotid intima-media thickness (CIMT) or carotid plaque are common manifestations of generalized atherosclerosis, closely associated with increased risk of stroke and myocardial infarction [5]. Therefore, early identification of CAS is essential for the management of diabetic patients.

Diabetes mellitus (DM) associated atherosclerosis can lead to complications in all major vascular beds, including the carotid vessels, coronary arteries, and lower extremity arteries [6,7]. The early detection of atherosclerosis mainly focuses on the carotid artery, as it is easily accessible to detect abnormality by noninvasive ultrasonic examination [8]. Atherosclerosis and its cardiovascular complications are the main cause of death in patients with type 2 diabetes mellitus (T2DM) [9]. These conditions impose great burdens on the health of community-dwelling individuals [10]. An early identification of affected individuals and comprehensive treatment can prevent and delay CAS risk [11]. Slowing the development and progression of CAS remains an unmet clinical need in patients with T2DM. For developing countries, there are still some T2DM patients who can not afford the cost of carotid artery ultrasound examination. Thus, investigation of effective predictors of CAS in patients with T2DM is very important and necessary. We expect that a routine blood test can calculate an index to predict the risk of CAS in patients with T2DM. Recently, triglyceride glucose (TyG) index has attracted our attention. 
TyG index has been widely used as a reliable surrogate marker of insulin resistance. TyG index has been demonstrated to have a high sensitivity and specificity for recognizing insulin resistance [12]. TyG index is calculated using levels of triacylglycerol (TG) and fasting blood glucose (FPG), TG and FPG are low-cost conventional biochemical testing items, so TyG index is economical, simple, and highly operable, and can be widely used. The hyperinsulinemic- euglycemic clamp (HIEC) and intravenous glucose tolerance test, gold standards for measuring insulin resistance, are used in research but not in clinical practice, due to the complicated operation and money consumption [13]. Although there are other markers of insulin resistance, such as the homeostasis model assessment of insulin resistance (HOMA-IR), but HOMA-IR is calculated using levels of endogenous insulin, patients with diabetes mellitus often receive treatment with insulin, which hampers accurate measurement of endogenous insulin [14].

In addition, a large cohort study proposed that a higher TyG index increases the risk of CAS incidence in the general population in China [15]. Studies have also shown that TyG index has a better correlation with CAS than HOMA-IR [12]. However, the relationship between TyG index and CAS in patients with T2DM has, so far, not been studied in detail in the literature, it might be linked to insulin resistance. Thus, we investigated the correlation between TyG index and CAS in patients with T2DM in crosssectional studies. Our study was to fill this knowledge gap.

\section{Materials And Methods Study population}

The research objects were from the endocrinology database center of Southwest Medical University (National Standardized Metabolic Disease Management Center). A total of 1896 consecutive patients were diagnosed with T2DM and underwent a complete carotid artery ultrasound examination from June 2017 to January 2021 in the Affiliated Hospital of Southwest Medical University. Inclusion criteria: patients diagnosed with T2DM and underwent a complete carotid artery ultrasound examination. Exclusion criteria: patients with age < 40 years old, T1DM, gestational diabetes, other special types of DM, or with severe infection, immune dysfunction, or malignant tumor, incomplete clinical data were excluded. Ultimately, 1476 patients with T2DM were enrolled in this cross-sectional study to elucidate the predictive value of TyG index for CAS in patients with T2DM (Fig. 1).

\section{Data Collection and measurement}

Each patient received a normative questionnaire. Demographic characteristics, behavioral risk factors, medical history, and physical examination were conducted by trained staff in Department of Endocrinology, Affiliated Hospital of Southwest Medical University. Age, sex, the duration of T2DM, smoking, alcohol consumption, the history of hypertension, the history of dyslipidaemia were self-reported. Smoking is defined as smoking $>1$ cigarette/day, duration $>1$ year. Drinking is defined as drinking $\geq 50 \mathrm{~g} /$ month in the past 3 months. Blood pressure was calculated using theaverage of 3 measurements at 1-minute intervals after 5 minutes of rest.

Physical examinations included the measurement of height, weight, waist circumference (WC), hip circumference, diastolic blood pressure (DBP), systolic blood pressure (SBP). Anthropometric measurements were measured following standardized protocols from the World Health Organization (WHO). WC was measured with an inelastic tape to the nearest $0.1 \mathrm{~cm}$ at a midpoint between the bottom of the rib cage and the top of the iliac crest at the end of exhalation. Blood pressure was measured by trained professionals, using an electronic sphygmomanometer (OMRON HEM-7200), and each participant was measured twice, resting for at least 20 min before measurements were taken. And body mass index (BMI) was calculated as body weight (in $\mathrm{kg}$ ) divided by the square of height (in $\mathrm{m} ; \mathrm{kg} / \mathrm{m} 2$ ). Omron visceral fat detection device HDS-2000 was used to measure visceral fat area (VFA) and subcutaneous fat area (SFA). We took the average of these readings.

Blood samples were collected to test FPG, glycosylated hemoglobin (HbA1c), alanine aminotransferase (ALT), aspartate aminotransferase (AST), alkaline phosphatase (ALP), $\mathrm{Y}$-Glutamyl transpeptidase ( $\mathrm{Y}-\mathrm{GT}), \mathrm{TG}, \mathrm{TC}, \mathrm{HDL}-\mathrm{C}, \mathrm{LDL}-\mathrm{C}$. All study subjects received a light diet after admission and fasted for at least 8 hours at night. In the next morning, $5 \mathrm{~mL}$ of venous blood was drawn on an empty stomach, the serum was separated, and FPG was determined by glucose oxidase method; HbA1c was

Page 3/16 
determined by high performance liquid chromatography; fully automated biochemical analysis The instrument (Hitachi, 7600) detects the levels of blood lipids and liver function.

\section{Definitions}

Hypertension is defined as the blood pressure is greater than or equal to $140 / 90 \mathrm{mmHg}$ three times on different days, or the antihypertensive drugs are used [16]. Dyslipidaemia was defined as having one or more of the following results: TG $\geq 2.26$ $\mathrm{mmol} / \mathrm{L}$, total cholesterol $(\mathrm{TC}) \geq 6.22 \mathrm{mmol} / \mathrm{L}$, high-density lipoprotein cholesterol (HDL-C) $\leq 1.04 \mathrm{mmol} / \mathrm{L}$, low-density lipoprotein cholesterol (LDL-C) $\geq 4.14 \mathrm{mmol} / \mathrm{L}$, self-reported diagnosis of dyslipidemia, or taking cholesterol-lowering medications [17]. Diabetes mellitus was defined as fasting plasma glucose $\geq 7.0 \mathrm{mmol} / \mathrm{L}$, and / or random blood glucose $(\mathrm{RBG}) \geq 11.1 \mathrm{mmol} / \mathrm{L}$, and / or 2-h plasma glucose level after oral glucose tolerance test (OGTT) $\geq 11.1 \mathrm{mmol} / \mathrm{L}$, self-reported diagnosis of diabetes mellitus, or use of oral hypoglycemic agents or insulin injection [18].

\section{Carotid Ultrasonography}

Carotid artery ultrasound examination: All patients had a complete carotid artery ultrasound examination. Use PHILIPS EPIQ7 color doppler ultrasound diagnostic apparatus for inspection, the frequency of the probe is $4.0-12.0 \mathrm{MHZ}$, all carotid artery ultrasound examinations are completed by 2 senior sonographers, one examines, the other records, and after the end, check and verify Enter the inspection results. The patient lies flat, head back and turned to the opposite side. The neck to be examined is completely exposed. The probe is gradually moved from the front of the neck to the back of the neck. Measure the thickness of the intima media at the proximal and distal ends at $1 \mathrm{~cm}$, and take the average value of 3 points as the CIMT value on the left and right sides, and then take the average value of the CIMT on the left and right sides as the final CIMT value, and issue an ultrasound report. The mean value of three right and left measurements was used to Indentify increased CIMT. A carotid plaque was defined as a focal wall thickening $>50 \%$ of the surrounding IMT or its CIMT $\geq 1.5 \mathrm{~mm}$. The presence of CAS was defined as having CIMT $\geq 1.0 \mathrm{~mm}$ or carotid plaque [19].

\section{Calculation of TyG index and grouping methods}

TyG index was calculated as: In [fasting triglycerides $(\mathrm{mg} / \mathrm{dL}) \times$ fasting glucose $(\mathrm{mg} / \mathrm{dL}) / 2$ ] [20]. In addition, the patients with T2DM were also divided into tertiles according to their TyG index levels (Tertile 1: TyG index $\leq$ 9.14; Tertile 2: $9.14<$ TyG index $\leq$ 9.77; Tertile 3: TyG index > 9.77). Blood pressure: normal blood pressure is $\mathrm{SBP}<130 \mathrm{mmHg}$ and $\mathrm{DBP}<80 \mathrm{mmHg}$, no history of hypertension; high-normal blood pressure is SBP 130-140 mmHg or DBP $80-90 \mathrm{mmHg}$, no history of hypertension; hypertension is SBP $\geq 140 \mathrm{mmHg}$ or DBP $\geq 90 \mathrm{mmHg}$, or previously diagnosed as hypertension and are using antihypertensive drugs [19]. BMI: Normal (BMI $\left.<24 \mathrm{Kg} / \mathrm{m}^{2}\right)$; Overweight $\left(24 \mathrm{Kg} / \mathrm{m}^{2} \leq \mathrm{BMI}<28 \mathrm{Kg} / \mathrm{m}^{2}\right)$; Obesity $\left(\mathrm{BMI} \geq 28 \mathrm{Kg} / \mathrm{m}^{2}\right)$ [21].

\section{Statistical Analyses}

Statistical analyses were undertaken using SPSS 26.0 (IBM, Armonk, NY, USA). The Kolmogorov-Smirnov Z-test was used to verify continuous variables with a normal distribution. Variables with an approximately normal distribution are expressed as the mean \pm standard deviation. Variables with a non-normal distribution are presented as median (interquartile range). Numerical variables in three sets of samples are compared between groups using analysis of variance (ANOVA) if they obey the normal distribution, whereas nonparametric tests (Kruskal-Wallis $H$-test) are used if they do not obey the normal distribution; categorical variables are described as a frequency or percentage, and the chi-square test was used for group comparisons, followed by posthoc analysis with Bonferroni correction.

TyG index was divided into three tertiles, and participants were stratified into groups based on "low", "median" and "high" values accordingly, which were named Tertile1-Tertile3. The odds ratios $(O R)$ and $95 \%$ confidence intervals $(95 \% \mathrm{Cl})$ of Tertile 2 and Tertile3 were calculated with reference to Tertile 1 . The $P$ values for trends were obtained using the tertiles level as an ordinal variable. The Subgroup analysis of TyG index and CAS risk was analyzed by binary logistic regression in Figure 2 . The results of the stratified study are presented through forest plots using $\mathrm{R}$ (www.R-project.org/). We created two binary logistic regression models in the cross-sectional study, to estimate the Independent association between TyG index and CAS while adjusting for potential confounders. The variables in these models are shown in Table 3. All reported $P$ values were 2-sided, with a $P<0.05$ considered statistically significant. 
Table 3

Association between TyG index and CAS in patients with T2DM

\begin{tabular}{|c|c|c|c|c|}
\hline \multirow[t]{3}{*}{ TyG index } & \multicolumn{4}{|l|}{ CAS } \\
\hline & \multicolumn{2}{|l|}{ Model 1} & \multicolumn{2}{|l|}{ Model 2} \\
\hline & OR $(95 \% \mathrm{Cl})$ & $P$ for trend & OR $(95 \% \mathrm{Cl})$ & $P$ for trend \\
\hline Tertile $1(n=492)$ & 1 & & 1 & \\
\hline Tertile $2(n=492)$ & $1.194(0.925,1.540)$ & 0.173 & $1.105(0.852,1.434)$ & 0.451 \\
\hline Tertile $3(n=492)$ & $1.633(1.258,2.119)$ & 0.001 & $1.451(1.107,1.902)$ & 0.007 \\
\hline \multicolumn{5}{|c|}{ Model 1: No adjustment for confounding factors. } \\
\hline \multicolumn{5}{|c|}{ Model 2: Adjusted for SBP, HbA1c, Hypertension in addition to the variables in Model 1.} \\
\hline$P$ value $<0.05$ wa & considered statistica & / significant. & & \\
\hline
\end{tabular}

\section{Results}

\section{General characteristics of the study population}

Table 1 presents the clinical characteristics of 1476 subjects according to tertiles of the TyG index. The mean age of participants was 58 (range, 40-78) years, and $48.6 \%$ were men. The prevalence of CAS showed a significant difference among the three groups $(P<0.001)$. With an increase in TyG index, participants tended to be older, with a higher level of diabetes duration, history of dyslipidaemia, weight, BMI, WC, hip circumference, DBP, SBP, VFA, SFA, FPG, 2hFPG, HbA1c, ALP, y-GT, TG, TC, LDL-C; with a lower level of HDL-C $(P<0.05$ for all). 
Table 1

Clinical characteristics of subjects by tertiles of TyG index.

\begin{tabular}{|c|c|c|c|c|c|}
\hline Variable & $\begin{array}{l}\text { Total } \\
(n=1476)\end{array}$ & $\begin{array}{l}\text { Tertile } 1 \\
(n=492)\end{array}$ & $\begin{array}{l}\text { Tertile } 2 \\
(n=492)\end{array}$ & $\begin{array}{l}\text { Tertile } 3 \\
(n=492)\end{array}$ & $P$ value \\
\hline Male, $\mathrm{n}(\%)$ & $718(48.6 \%)$ & $234(47.6 \%)$ & $236(48.0 \%)$ & $248(50.4 \%)$ & $0.627^{a}$ \\
\hline Age (y) & $58.0(51.0,65.0)$ & $55.0(50.0,64.0)$ & $57.0(51 \cdot 0,65.0)$ * & $60 \cdot 0(53 \cdot 0,66 \cdot 0)^{\star \star \#}$ & $<0.001$ \\
\hline $\begin{array}{l}\text { Diabetes } \\
\text { duration }(\mathrm{m})\end{array}$ & $80.0(24.0,146.8)$ & $77.0(18.0,145.0)$ & $79.0(19.0,133.8)$ & $83.0(37.5,156.8)^{\star}$ & 0.016 \\
\hline $\begin{array}{l}\text { Smoking, } \mathrm{n} \\
(\%)\end{array}$ & $515(34.9 \%)$ & $157(31.9 \%)$ & $177(36.0 \%)$ & $181(36.8 \%)$ & $0.228^{a}$ \\
\hline $\begin{array}{l}\text { Consumption } \\
\text { of alcohol, } n \\
(\%)\end{array}$ & $594(40.2 \%)$ & $184(37.4 \%)$ & $197(40.0 \%)$ & $213(43.3 \%)$ & $0.168^{a}$ \\
\hline $\begin{array}{l}\text { Hypertension, } \\
\text { n (\%) }\end{array}$ & $583(59.4 \%)$ & $196(56.9 \%)$ & $193(60.2 \%)$ & $194(61.2 \%)$ & $0.980^{a}$ \\
\hline $\begin{array}{l}\text { Dyslipidaemia, } \\
\text { n (\%) }\end{array}$ & $268(18.2 \%)$ & $67(13.6 \%)$ & $90(18.3 \%)^{*}$ & $111(22.6 \%)^{\star \star \star}$ & $<0.001^{a}$ \\
\hline Height $(\mathrm{cm})$ & $160.0(153.0,166.0)$ & $159.0(152.5,166.0)$ & $160.0(155.0,166.0)$ & $160.0(153.0,166.0)$ & 0.057 \\
\hline Weight (Kg) & $63.0(55.0,70.0)$ & $60.0(54.0,68.0)$ & $64.5(57.0,71.0)^{\star \star}$ & $64.0(56.5,72.0)^{\star \star}$ & $<0.001$ \\
\hline BMI $\left(\mathrm{Kg} / \mathrm{m}^{2}\right)$ & $24.50(22.40,26.80)$ & $23.68(21.50,25.90)$ & $24.80(22.80,27.28)^{\star \star}$ & $25.10(23.00,27.00)^{\star \star}$ & $<0.001$ \\
\hline $\begin{array}{l}\text { Waist circum- } \\
\text { ference }(\mathrm{cm})\end{array}$ & $86.0(80.0,93.0)$ & $83.0(77.0,90.0)$ & $88.0(80.6,94.8)^{\star \star}$ & $88.0(82.0,94.0)^{\star \star}$ & $<0.001$ \\
\hline $\begin{array}{l}\text { Hip circumfe- } \\
\text { rence }(\mathrm{cm})\end{array}$ & $90.0(86.0,95.0)$ & $89.8(85.0,94.0)$ & $90.0(86.0,96.0)^{\star \star}$ & 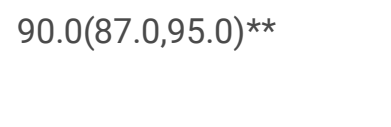 & $<0.001$ \\
\hline $\mathrm{DBP}(\mathrm{mmHg})$ & $80.0(73.0,87.0)$ & $78.0(71.0,85.0)$ & $81.0(74.0,87.0)$ & $82 \cdot 0(74.0,89.0) \star \star$ & $<0.001$ \\
\hline $\mathrm{SBP}(\mathrm{mmHg})$ & $137.0(122.0,149.0)$ & $136.0(124.0,152.0)$ & $138.0(124.0,152.0)$ & $139.0(126.0,156.0) \star$ & 0.279 \\
\hline VFA $\left(\mathrm{cm}^{2}\right)$ & $81.0(56.0,108.0)$ & $70.0(46.0,97.0)$ & $82 \cdot 0(60.0,110.8)^{\star \star}$ & $90.5(66.0,116.0)^{\star \star}$ & $<0.001$ \\
\hline $\mathrm{SFA}\left(\mathrm{cm}^{2}\right)$ & $152.0(116.0,190.0)$ & $138.0(100.3,183.8)$ & $157.5(121.3,202.0)^{\star \star}$ & $158.5(125.0,191.1)^{\star \star}$ & $<0.001$ \\
\hline FPG (mmol/L) & $8.90(7.10,11.55)$ & $7.10(6.0,8.4)$ & $9.20(7.4,11.5)^{\star \star}$ & $11.29(9.2,13.8)^{\star \star \# \# ~}$ & $<0.001$ \\
\hline $\begin{array}{l}2 \mathrm{hFPG} \\
(\mathrm{mmol} / \mathrm{L})\end{array}$ & $14.30(11.23,18.00)$ & $12.65(10.0,15.8)$ & $14.20(11.3,17.9)^{\star \star}$ & $16.30(13.1,19.5)^{\star \star \# \# ~}$ & $<0.001$ \\
\hline $\mathrm{HbA1c}(\%)$ & $9.40(7.60,11.18)$ & $8.50(7.10,10.40)$ & $9.30(7.80,11.20)^{\star \star}$ & $10.00(8.60,11.80)^{\star \star \# \# ~}$ & $<0.001$ \\
\hline $\operatorname{ALT}(\mathrm{U} / \mathrm{L})$ & $21.10(15.60,32.40)$ & $20.20(15.40,31.13)$ & $21.80(15.83,32.30)$ & $21.80(15.60,33.74)$ & 0.329 \\
\hline AST (U/L) & $19.40(15.40,25.23)$ & $19.50(15.83,24.55)$ & $19.40(15.20,25.30)$ & $19.20(15.10,25.68)$ & 0.498 \\
\hline $\operatorname{ALP}(U / L)$ & $82.00(64.90,100.68)$ & $75.90(61.60,95.33)$ & $80.75(64.43,96.98)$ & $89.25(73.40,105.95) \star \star \# \#$ & $<0.001$ \\
\hline
\end{tabular}

Data are expressed as mean \pm SD or median (25th, 75th percentile) for continuous variables and $n(\%)$ for categorical variables. a is the $\chi 2$ value, and the remalnder test statistic is the $Z$ value. All reported $P$ values were 2 -sided, with a $P<0.05$ considered statistically significant. The $P$ values stood for the overall differences among groups; * $P$ value $<0.05$, ** $P$ value $<0.01$ vs. Q1 group; ${ }^{*} P$ value $<0.05$, \#\# $P$ value $<0.01$ vs. Q2 group. 


\begin{tabular}{|c|c|c|c|c|c|}
\hline Variable & $\begin{array}{l}\text { Total } \\
(n=1476)\end{array}$ & $\begin{array}{l}\text { Tertile } 1 \\
(n=492)\end{array}$ & $\begin{array}{l}\text { Tertile } 2 \\
(n=492)\end{array}$ & $\begin{array}{l}\text { Tertile } 3 \\
(n=492)\end{array}$ & $P$ value \\
\hline Г-GT (U/L) & $24.70(16.40,40.93)$ & $18.70(13.53,30.83)$ & 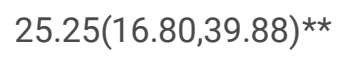 & $31.20(21.23,53.68)^{\star \star \# \# ~}$ & $<0.001$ \\
\hline TG (mmol/L) & $1.77(1.17,2.58)$ & $1.03(0.82,1.33)$ & $1.79(1.43,2.25)^{\star \star}$ & $3.08(2.35,3.97)^{\star \star \star \# \# ~}$ & $<0.001$ \\
\hline $\mathrm{TC}(\mathrm{mmol} / \mathrm{L})$ & $4.53(3.80,5.28)$ & $4.11(3.42,4.80)$ & $4.52(3.89,5.22)^{\star \star}$ & $4.99(4.21,5.83) \star \star \# \#$ & $<0.001$ \\
\hline $\begin{array}{l}\text { HDL-C } \\
(\mathrm{mmol} / \mathrm{L})\end{array}$ & $1.12(0.94,1.32)$ & $1.26(1.05,1.49)$ & $1.11(0.93,1.26)^{\star \star}$ & $1.03(0.87,1.19)^{\star \star \# \# ~}$ & $<0.001$ \\
\hline $\begin{array}{l}\text { LDL-C } \\
(\mathrm{mmol} / \mathrm{L})\end{array}$ & $2.71(2.06 .3 .43)$ & $2.44(1.76,3.12)$ & $2.79(2.23,3.54)^{\star \star}$ & 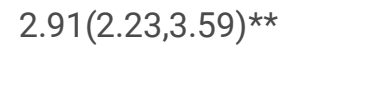 & $<0.001$ \\
\hline TyG index & $9.48(8.94,9.94)$ & $8.75(8.46,8.94)$ & $9.50(9.32,9.64)^{\star \star}$ & $10.12(9.95,10.45)^{\star \star \# \# ~}$ & $<0.001$ \\
\hline CAS, n (\%) & $920(62.3 \%)$ & $281(57.1 \%)$ & $302(61.4 \%)$ & $337(68.5 \%)^{\star \star}$ & $<0.001^{a}$ \\
\hline \multicolumn{6}{|c|}{ 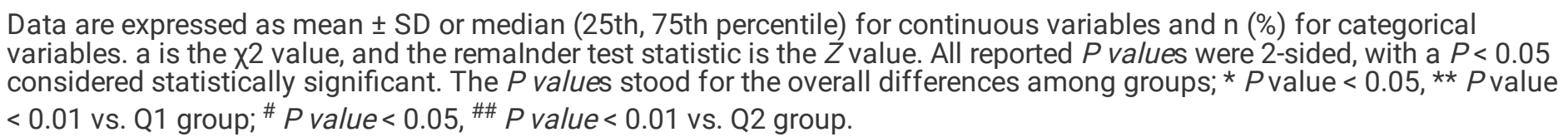 } \\
\hline
\end{tabular}

\section{Prevalence of CAS in patients with T2DM according to TyG index tertiles}

The prevalence of CAS in patients with T2DM increased with increasing TyG index tertiles (Fig. 2). The prevalence of CAS in patients with T2DM in Tertile1-Tertile3 were 57.1\% (281/492), 61.4\% (302/492) and 68.5\% (337/492), respectively. The prevalence of CAS in the three groups was compared, and the difference was statistically significant $\left(\chi^{2}=13.856, P<0.01\right)$. The prevalence of CAS in Tertile2 was higher than that in Tertile1, and the difference was not statistically significant $\left(\chi^{2}=1.856, P=\right.$ 0.173); the prevalence of CAS in Tertile 3 was greater than that in Tertile 1 , and the difference was statistically significant $\left(\chi^{2}=\right.$ 13.643, $P<0.01)$. The prevalence of CAS in Tertile 3 was higher than that in Tertile 1 , and the difference was statistically significant $\left(\chi^{2}=5.468, P<0.05\right)$.

\section{Logistic regression analysis of clinical variables and the risk of CAS in patients with T2DM}

Taking the occurrence of CAS in patients with T2DM as the dependent variable $(\mathrm{No}=0$, Yes=1), Univariate logistic regression analysis was used to screen the risk factors of CAS in patients with T2DM. Variables with Pless than 0.05 were included. Multivariate logistic regression analysis to analyze the risk factors of CAS in patients with T2DM (Because TyG index is calculated by TG and FPG, the multivariate logistic regression analysis was not included). Multivariate logistic regression analysis confirmed that the prevalence of CAS in patients with T2DM increased with the increase of SBP, HbA1c and TyG Index. Moreover, in T2DM patients with CAS, hypertension is also a risk factor (Table 2). 
Logistic regression analysis of clinical variables and the risk of CAS in patients with T2DM

\begin{tabular}{|c|c|c|c|c|}
\hline \multirow[t]{2}{*}{ Variable } & \multicolumn{2}{|l|}{ Univariate } & \multicolumn{2}{|l|}{ Multivariate } \\
\hline & OR $(95 \% \mathrm{Cl})$ & $P$ Value & OR $(95 \% \mathrm{Cl})$ & $P$ Value \\
\hline Male, n (\%) & $0.719(0.582,0.888)$ & 0.002 & $0.822(0.563,1.201)$ & 0.311 \\
\hline Age $(y)$ & $1.017(1.005,1.030)$ & 0.007 & $1.011(0.998,1.024)$ & 0.089 \\
\hline Diabetes duration (m) & $1.000(0.999,1.002)$ & 0.668 & & \\
\hline Smoking, n (\%) & $1.494(1.192,1.873)$ & 0.001 & $1.356(0.979,1.1 .877)$ & 0.067 \\
\hline Consumption of alcohol, n (\%) & $1.209(0.974,1.501)$ & 0.085 & & \\
\hline $\begin{array}{l}\text { Hypertension, } \\
\text { n (\%) }\end{array}$ & $1.548(1.243,1.928)$ & 0.001 & $1.396(1.078,1.808)$ & 0.011 \\
\hline Dyslipidaemia, n (\%) & $1.376(1.038,1.824)$ & 0.027 & $1.240(0.917,1.678)$ & 0.162 \\
\hline Height (cm) & $1.014(1.001,1.027)$ & 0.034 & $0.995(0.907,1.093)$ & 0.924 \\
\hline Weight (Kg) & $1.016(1.006,1.026)$ & 0.002 & $1.003(0.894,1.126)$ & 0.955 \\
\hline $\mathrm{BMI}\left(\mathrm{Kg} / \mathrm{m}^{2}\right)$ & $1.041(1.008,1.075)$ & 0.014 & $0.989(0.737,1.328)$ & 0.941 \\
\hline WC (cm) & $1.020(1.009,1.031)$ & 0.001 & $1.007(0.984,1.031)$ & 0.563 \\
\hline $\begin{array}{l}\text { Hip circumference } \\
(\mathrm{cm})\end{array}$ & $0.997(0.982,1.012)$ & 0.650 & & \\
\hline $\mathrm{DBP}(\mathrm{mmHg})$ & $1.009(0.999,1.018)$ & 0.082 & & \\
\hline $\mathrm{SBP}(\mathrm{mmHg})$ & $1.010(1.005,1.016)$ & 0.001 & $1.009(1.003,1.015)$ & 0.005 \\
\hline $\operatorname{VFA}\left(\mathrm{cm}^{2}\right)$ & $1.003(1.000,1.005)$ & 0.034 & $0.999(0.995,1.003)$ & 0.608 \\
\hline $\operatorname{SFA}\left(\mathrm{cm}^{2}\right)$ & $1.002(1.000,1.003)$ & 0.089 & & \\
\hline FPG (mmol/L) & $1.047(1.015,1.081)$ & 0.004 & & \\
\hline 2hFPG (mmol/L) & $1.034(1.011,1.057)$ & 0.004 & $1.005(0.978,1.031)$ & 0.736 \\
\hline HbA1c (\%) & $1.083(1.036,1.132)$ & 0.001 & $1.080(1.024,1.139)$ & 0.004 \\
\hline ALT (U/L) & $1.002(0.998,1.006)$ & 0.245 & & \\
\hline AST (U/L) & $1.003(0.997,1.009)$ & 0.337 & & \\
\hline ALP (U/L) & $1.001(0.999,1.004)$ & 0.335 & & \\
\hline Г-GT (U/L) & $1.001(0.999,1.002)$ & 0.329 & & \\
\hline TG (mmol/L) & $1.177(1.077,1.287)$ & 0.000 & & \\
\hline TC (mmol/L) & $1.032(0.950,1.121)$ & 0.453 & & \\
\hline $\mathrm{HDL}-\mathrm{C}(\mathrm{mmol} / \mathrm{L})$ & $0.583(0.426,0.798)$ & 0.001 & $0.863(0.607,1.226)$ & 0.410 \\
\hline LDL-C (mmol/L) & $1.092(0.987,1.207)$ & 0.087 & & \\
\hline TyG index & $1.460(1.254,1.701)$ & 0.001 & $1.265(1.059,1.510)$ & 0.010 \\
\hline
\end{tabular}


To assess the correlation of TyG index with CAS in patients with T2DM, we undertook binary logistic regression analysis of cross-sectional data. In Model 1, with the low tertile of TyG index set as the reference, TyG index in the top tertile was associated with a higher $O R$ for CAS $(O R=1.633,95 \% C l=1.258-2.119, P<0.001)$ after no adjustment for confounding factors (Model 1). After additional adjustment for systolic blood pressure, $\mathrm{HbA1c}$, hypertension in addition to the variables in Model 1, this trend (Model 2) was retained. With the low tertile of TyG index set as the reference, TyG index in the top tertile was associated with a higher $O R$ for CAS $(O R=1.451,95 \% C l=1.107-1.902, P=0.007)$ (Table 3). Participants in the high tertile of TyG index continued to have a higher prevalence of incident CAS compared with those in the low tertile.

\section{Subgroup analysis between the TyG index tertiles and the risk of carotid atherosclerosis}

Figure 3 presents the results of subgroup analysis showing the relationship between TyG index and CAS. According to gender (Fig. 3a), age (Fig. 3b), blood pressure level (Fig. 3c), and BMI level (Fig. 3d), the population was further divided into groups, and the subgroup analysis was performed. The results showed that Tertile 1 of each group was used as the control, and the risk of CAS in Tertile 3 of female was higher than that of men, with an OR score of 0.827 ( $95 \% \mathrm{Cl}=1.245-2.682, P<0.05)$; the risk of CAS was increased in patients who were younger than 65 years old was increased, with an $O R$ score of $1.500(95 \% \mathrm{Cl}=1.098$ 2.050, $P<0.05)$; the risk of CAS in patients with hypertension in Tertile 3 was increased, with an OR score of $1.538(95 \% \mathrm{Cl}=$ 1.020-2.319, $P<0.05)$; the risk of CAS in Tertile 3 of obese patients was increased, with an $O R$ score of $2.207(95 \% \mathrm{Cl}=1.061$ $4.594, P<0.05)$.

\section{Discussion}

Atherosclerosis is a chronic disease of the arteries characterized by inflammation and plaque building in the arterial wall, eventually leading to stenosis of the vessel. Carotid atherosclerosis (CAS), which is associated with increased cardiovascular risk [22]. Therefore, methods for the early detection and prevention of CAS would be of clinical and societal value.

The present study provides strong evidence that an increasing TyG index is Independently associated with an increased risk of CAS in patients with T2DM. TyG index allow an early detection of carotid atherosclerotic burden and at the same time enhance our ability to determine those individuals who are at greater risk for CAS.

As mentioned above, the HIEC is considered the current gold standard to determine insulin resistance [13]; however, as an alternative strategy, TyG index has become an attractive option due to the highly available and inexpensive biochemical markers needed for its calculation [23, 24]. Generally, TyG index is dysregulated if insulin resistance occurs. Thus, TyG index has been described as a biochemical marker of insulin resistance.

Insulin resistance is one of the first metabolic abnormalities leading to the development of T2DM, and it is known to be a key mediator of its pathogenesis [25-27]. Insulin resistance is associated with CAS development in patients with T2DM, but the mechanism of action has not been elucidated fully. Insulin is a vascular hormone, it is not only a hormone regulating the glucose level in blood, it is also a signaling molecule in many tissues and cells [28, 29]. The alterations in vascular homeostasis due to endothelial and smooth muscle cell dysfunction are the main features of diabetic vasculopathy favouring a proinflammatory/thrombotic state which ultimately leads to atherothrombosis [2]. Hyperglycemia, insulin resistance, and inflammation and metabolic derangements associated with concomitant obesity cause endothelial vasodilator and fibrinolytic dysfunction [30]. A large cohort study found that insulin resistance measured by short insulin tolerance test is Independently associated with CAS in patients with T2DM [31]. The research also proved that individuals with metabolic syndrome are at an increased risk for CAS compared to those without metabolic syndrome [32]. These studies suggested that TyG index is of great value for predicting CAS. Careful consideration of the insulin resistance mechanism would help clarify the exact mechanism by which TyG index of T2DM patients contributes to atherosclerosis.

The correlation of TyG index with diabetic macrovascular disease is unclear, and a study is needed to investigate the predictive value of TyG index for CAS in patients with T2DM. Our cross-sectional study enrolled a relatively large sample with T2DM. We found that an increased TyG index was associated with a high risk of CAS. This is the first study to discover the association of

Page 9/16 
TyG index with CAS in patients with T2DM. Furthermore, as a proxy for insulin resistance, TyG index has the advantage of being clinically applicable because TG and glucose concentrations are measured routinely in patients with T2DM, some patients with T2DM in developing countries refuse carotid ultrasound examination due to economic reasons.

Our Subgroup analysis also showed that when the patient is female, or younger than 65 , or suffering from hypertension and obesity, the risk of CAS in patients with T2DM was significantly increased when TyG index increased. Insulin resistance may play a key role. Previous studies have found that female with T2DM are more likely to have dyslipidemia [33], abdominal obesity [34] and hypertension [35], and their vascular endothelial function damage and thrombosis risk are higher than men [36], and the risk of macrovascular disease is also higher. Studies have pointed out that the rate of progression of Chinese carotid atherosclerosis with age is more extreme[37]. But in this article, with the increase of TyG index, patients with T2DM younger than 65 years of age are at higher risk of developing CAS. The reason may be related to insufficient sample size. Obesity is associated with an increased risk of insulin resistance and T2DM [38]. Obesity are also the main risk factors for the development of CAS and cardiovascular disease [39]. Insulin resistance is associated with a variety of cardiovascular disease risk factors including central obesity, essential hypertriglyceridemia, and low HDL-C [40], this is consistent with our research results. Prevalence of obesity and the metabolic syndrome is rapidly increasing in developing countries, leading to increased morbidity and mortality due to T2DM and cardiovascular disease [41]. International health agencies and related governments should focus on TyG index of obese patients with T2DM in developing countries. Therefore, it is recommended that patients with T2DM should actively control their weight, blood pressure and blood sugar to reduce the risk of macrovascular events.

\section{Study Strengths And Limitations}

This is the first study to confirm a relationship between TyG index and CAS in patients with T2DM through the use of the endocrinology database center of Southwest Medical University (National Standardized Metabolic Disease Management Center) from Chinese adults. However, This study had two main shortcomings. First, the sample size in this study was relatively small: validation of our data on a larger population is needed. Another of the limitations of our study was that we could not analyze the plaque composition in our study subjects. As plaque composition can be a better indicator of cardiovascular outcome [42], further studies that include plaque composition in the evaluation of atherosclerosis are recommended. Finally, due to the cross-sectional study design, we could not assess causality between TyG index and CAS.

\section{Conclusions}

In conclusion, a higher TyG index was associated with a higher probability of incident CAS in patients with T2DM. TyG index is more sensitive to the prediction of CAS in female, younger than 65 years old, with hypertension and obesity in patients with T2DM, and we should be paid more attention to. Longitudinal cohort studies and exploratory studies are needed to investigate the relationship between the TyG index and CAS in patients with T2DM.

\section{Abbreviations}

TyG index: Triglyceride-glucose index; CAS: Carotid atherosclerosis; T2DM: Type 2 diabetes mellitus; T1DM: Type 1 diabetes mellitus; CIMT: Carotid intima-media thickness; DM: Diabetes mellitus $\llbracket V F A$ : Visceral fat area; SFA: Subcutaneous fat area; BMI: Body mass index; FPG: Fasting plasma glucose; TG: Triglyceride; TC: Total cholesterol; HDL-C: High density lipoprotein cholesterol; LDL-C: Low density lipoprotein cholesterol; ALT: Alanine aminotransferase; AST: Aspartate aminotransferase; ALP: Alkaline phosphatase; ү-GT: ү-Glutamyl transpeptidase; DBP: Diastolic blood pressure; SBP: Systolic blood pressure; RGB: Random blood glucose; OGTT: Oral glucose tolerance test; HIEC: Hyperinsulinemic- euglycemic clamp; HOMA-IR: Homeostatic model assessment of insulin resistance; $\mathrm{Cl}$ : Confidence interval; OR: Odds ratio.

\section{Declarations}

\section{Ethics approval and consent to participant}

Page 10/16 
The study was conducted in accordance with the Declaration of Helsinki 1964 and its later amendments. The study protocol (grant No. 2018017) was approved by the Ethics Committee on Human Studies at the Affiliated Hospital of Southwest Medical University (Luzhou, Sichuan). Written consent was obtained from all participants in the original study, no name was published in any form, all participants' data remained confidential after data collection, and each participant was recognized by a code.

\section{Consent for publication}

Not applicable.

\section{Availability of data and materials}

The datasets used and/or analyzed during the current study are available from

the corresponding author on reasonable request.

\section{Competing interests}

The authors declare that they have no conflict of interest.

\section{Funding}

None.

\section{Authors' contributions}

$\mathrm{HL}$ and JL made substantial contributions to conception, design of the study. HL contributed to the study design. YYL and YL contributed to the acquisition and interpretation of the data. HL performed the statistical analysis and prepared the first version of the manuscript. QW revised the manuscript critically for essential intellectual content. All authors read and approved the final manuscript.

\section{Acknowledgements}

We appreciate all participants who took part in our study.

\section{References}

1. Underhill HR, Hatsukami TS, Fayad ZA, et al. MRI of carotid atherosclerosis: clinical implications and future directions. Nat Rev Cardiol. 2010 Mar;7(3):165-73.

2. Paneni F, Beckman JA, Creager MA, et al. Diabetes and vascular disease: pathophysiology, clinical consequences, and medical therapy: part I. Eur Heart J. 2013 Aug;34(31):2436-43.

3. Bornfeldt KE, Tabas I. Insulin resistance, hyperglycemia, and atherosclerosis. Cell Metab. 2011 Nov 2;14(5):575-85.

4. Ishizaka N, Ishizaka Y, Takahashi E, et al. Association between insulin resistance and carotid arteriosclerosis in subjects with normal fasting glucose and normal glucose tolerance. Arterioscler Thromb Vasc Biol. 2003 Feb 1;23(2):295-301.

5. Kadoglou NP, lliadis F, Liapis CD. Exercise and carotid atherosclerosis. Eur J Vasc Endovasc Surg. 2008 Mar;35(3):264-72.

6. Marso SP, Hiatt WR. Peripheral arterial disease in patients with diabetes. J Am Coll Cardiol. 2006 Mar 7;47(5):921-9.

7. Forbang NI, McDermott MM, Liao Y, et al. Associations of diabetes mellitus and other cardiovascular disease risk factors with decline in the ankle-brachial index. Vasc Med. 2014 Dec;19(6):465-72.

8. Nguyen-Thanh HT, Benzaquen BS. Screening for subclinical coronary artery disease measuring carotid intima media thickness. Am J Cardiol. 2009 Nov 15;104(10):1383-8.

9. Ramuš SM, Petrovič D. Genetic Variations and Subclinical Markers of Carotid Atherosclerosis in Patients with Type 2 Diabetes Mellitus. Curr Vasc Pharmacol. 2019;17(1):16-24. 
10. Herrington W, Lacey B, Sherliker P, et al. Epidemiology of Atherosclerosis and the Potential to Reduce the Global Burden of Atherothrombotic Disease. Circ Res. 2016 Feb 19;118(4):535-46.

11. Marks D, Thorogood M, Neil HA, et al. A review on the diagnosis, natural history, and treatment of familial hypercholesterolaemia. Atherosclerosis. 2003 May;168(1):1-14.

12. Unger G, Benozzi SF, Perruzza F, et al. Triglycerides and glucose index: a useful indicator of insulin resistance. Endocrinol Nutr. 2014 Dec;61(10):533-40. English, Spanish.

13. Minh HV, Tien HA, Sinh CT, et al. Assessment of preferred methods to measure insulin resistance in Asian patients with hypertension. J Clin Hypertens (Greenwich). 2021 Mar;23(3):529-537.

14. Matthews DR, Hosker JP, Rudenski AS, et al. Homeostasis model assessment: insulin resistance and beta-cell function from fasting plasma glucose and insulin concentrations in man. Diabetologia. 1985 Jul;28(7):412-9.

15. Wu Z, Wang J, Li Z, et al. Triglyceride glucose index and carotid atherosclerosis incidence in the Chinese population: A prospective cohort study. Nutr Metab Cardiovasc Dis. 2021 Jun 30;31(7):2042-2050.

16. Yao GH, Chen XY, Zhang Q, et al. A Novel Mathematical Model for Correcting the Physiologic Variance of Two-Dimensional Echocardiographic Measurements in Healthy Chinese Adults. J Am Soc Echocardiogr. 2019 Jul;32(7):876-883.e11.

17. Joint Committee for Developing Chinese guidelines on, $P$ and Treatment of Dyslipidemia in, A, 28 [Chinese guidelines on prevention and treatment of dyslipidemia in adults], Zhonghua xin xue guan bing za zhi, 2007;35:390-419.

18. Alberti KG, Zimmet PZ. Definition, diagnosis and classification of diabetes mellitus and its complications. Part 1: diagnosis and classification of diabetes mellitus provisional report of a WHO consultation. Diabet Med. 1998 Jul;15(7):539-53.

19. Wang X, Li W, Song F, et al. Carotid Atherosclerosis Detected by Ultrasonography: A National Cross-Sectional Study. J Am Heart Assoc. 2018 Apr 5;7(8):e008701.

20. Guerrero-Romero F, Simental-Mendía LE, González-Ortiz M, et al. The product of triglycerides and glucose, a simple measure of insulin sensitivity. Comparison with the euglycemic-hyperinsulinemic clamp. J Clin Endocrinol Metab. 2010 Jul;95(7):3347-51.

21. You Y, Teng W, Wang J, et al. Hypertension and physical activity in middle-aged and older adults in China. Sci Rep. 2018 Oct 31;8(1):16098.

22. Forgo B, Medda E, Hernyes A, et al. Carotid Artery Atherosclerosis: A Review on Heritability and Genetics. Twin Res Hum Genet. 2018 Oct;21(5):333-346.

23. Singh B, Saxena A. Surrogate markers of insulin resistance: A review. World J Diabetes. 2010 May 15;1(2):36-47.

24. Simental-Mendía LE, Rodríguez-Morán M, Guerrero-Romero F. The product of fasting glucose and triglycerides as surrogate for identifying insulin resistance in apparently healthy subjects. Metab Syndr Relat Disord. 2008 Dec;6(4):299-304.

25. Martin BC, Warram JH, Krolewski AS, et al. Role of glucose and insulin resistance in development of type 2 diabetes mellitus: results of a 25-year follow-up study. Lancet. 1992 Oct 17;340(8825):925-9.

26. Weyer C, Bogardus C, Mott DM, et al. The natural history of insulin secretory dysfunction and insulin resistance in the pathogenesis of type 2 diabetes mellitus. J Clin Invest. 1999 Sep;104(6):787-94.

27. Bonora E, Kiechl S, Willeit J, et al. Population-based incidence rates and risk factors for type 2 diabetes in white individuals: the Bruneck study. Diabetes. 2004 Jul;53(7):1782-9.

28. Gnudi L, Coward RJM, Long DA. Diabetic Nephropathy: Perspective on Novel Molecular Mechanisms. Trends Endocrinol Metab. 2016 Nov;27(11):820-830.

29. Anfossi G, Russo I, Doronzo G, et al. Contribution of insulin resistance to vascular dysfunction. Arch Physiol Biochem. 2009 Oct;115(4):199-217.

30. Wasserman DH, Wang TJ, Brown NJ. The Vasculature in Prediabetes. Circ Res. 2018 Apr 13;122(8):1135-1150.

31. Park SW, Kim SK, Cho YW, et al. Insulin resistance and carotid atherosclerosis in patients with type 2 diabetes. Atherosclerosis. 2009 Jul;205(1):309-13.

32. Zhou PA, Zhang CH, Chen YR, et al. Association between Metabolic Syndrome and Carotid Atherosclerosis: A Crosssectional Study in Northern China. Biomed Environ Sci. 2019 Dec;32(12):914-921.

Page $12 / 16$ 
33. Vimalananda VG, Miller DR, Palnati M, et al. Gender disparities in lipid-lowering therapy among veterans with diabetes. Womens Health Issues. 2011 Jul-Aug;21(4 Suppl):S176-81.

34. Penno G, Solini A, Bonora E, et al. Renal Insufficiency And Cardiovascular Events (RIACE) study, group. Gender differences in cardiovascular disease risk factors, treatments and complications in patients with type 2 diabetes: the RIACE Italian multicentre study. J Intern Med. 2013 Aug;274(2):176-91.

35. Giri BR, Sharma KP, Chapagai RN, et al. Diabetes and hypertension in urban bhutanese men and women. Indian J Community Med. 2013 Jul;38(3):138-43.

36. Donahue RP, Rejman K, Rafalson LB, et al. Sex differences in endothelial function markers before conversion to prediabetes: does the clock start ticking earlier among women? The Western New York Study. Diabetes Care. 2007 Feb;30(2):354-9.

37. Clarke R, Du H, Kurmi O, et al. China Kadoorie Biobank Collaborative Group. Burden of carotid artery atherosclerosis in Chinese adults: Implications for future risk of cardiovascular diseases. Eur J Prev Cardiol. 2017 Apr;24(6):647-656.

38. Al-Sulaiti H, Diboun I, Agha MV, et al. Metabolic signature of obesity-associated insulin resistance and type 2 diabetes. J Transl Med. 2019 Oct 22;17(1):348.

39. Li B, Lai X, Yan C, et al. The associations between neutrophil-to-lymphocyte ratio and the Chinese Visceral Adiposity index, and carotid atherosclerosis and atherosclerotic cardiovascular disease risk. Exp Gerontol. 2020 0ct 1;139:111019.

40. Reaven GM. Banting lecture 1988. Role of insulin resistance in human disease. Diabetes. 1988 Dec;37(12):1595-607.

41. Misra A, Khurana L. Obesity and the metabolic syndrome in developing countries. J Clin Endocrinol Metab. 2008 Nov;93(11 Suppl 1):S9-30.

42. Pavel Poredoš, Mateja Kaja Ježovnik, Anže Gošte. Is it possible to estimate cerebro-vascular risk on the basis of the composition of carotid atherosclerotic plaques? Zdravniški Vestnik,2012,81(2).

\section{Figures}




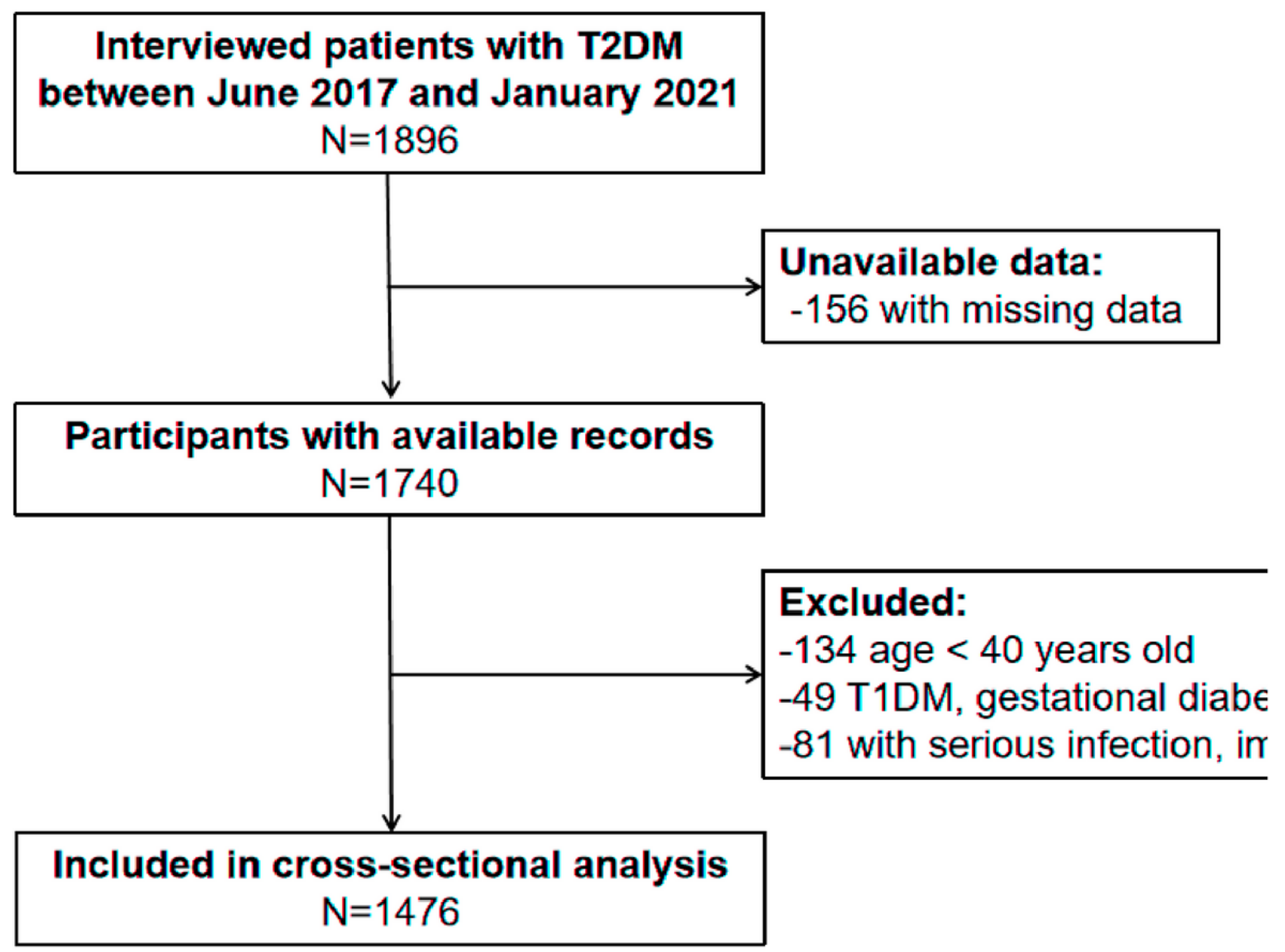

Figure 1

patients with age $<40$ years old, T1DM, gestational diabetes, other special types of DM, or with severe infection, immune dysfunction, or malignant tumor, incomplete clinical data were excluded. Ultimately, 1476 patients with T2DM were enrolled in this cross-sectional study to elucidate the predictive value of TyG index for CAS in patients with T2DM (Fig. 1). 
Prevalence of CAS in patients with T2DM according to TyG index tertil

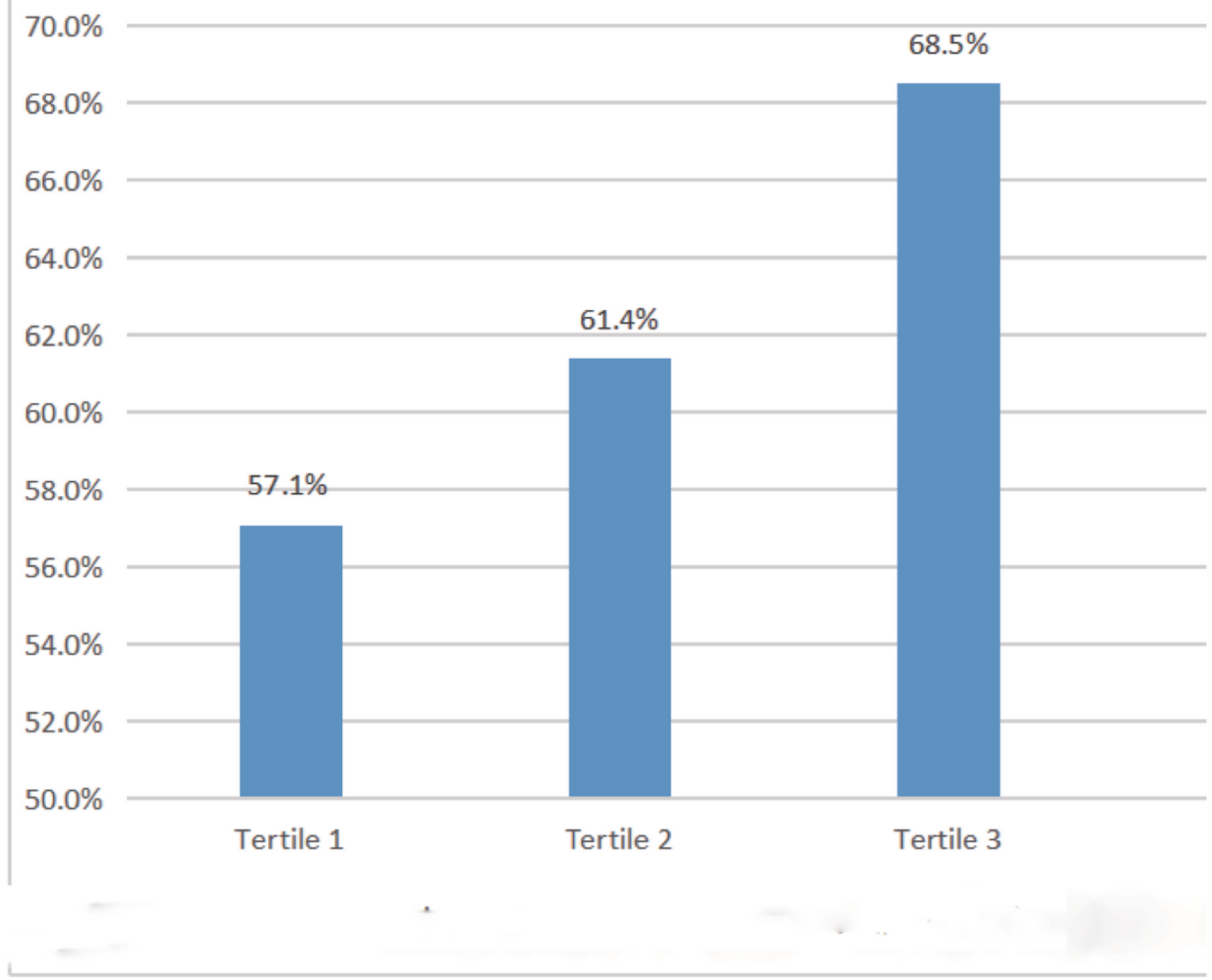

Figure 2

The prevalence of CAS in patients with T2DM increased with increasing TyG index tertiles (Fig.2) 
(a)

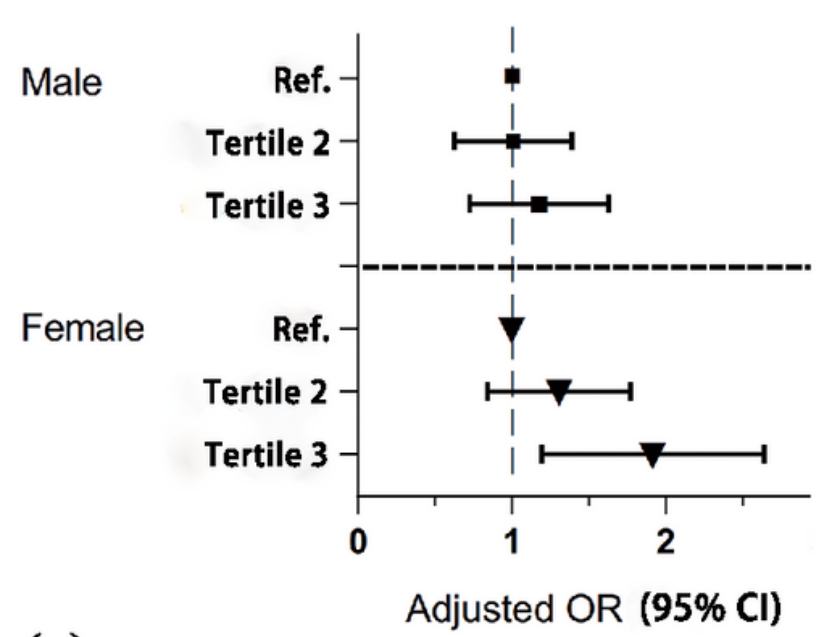

(c)

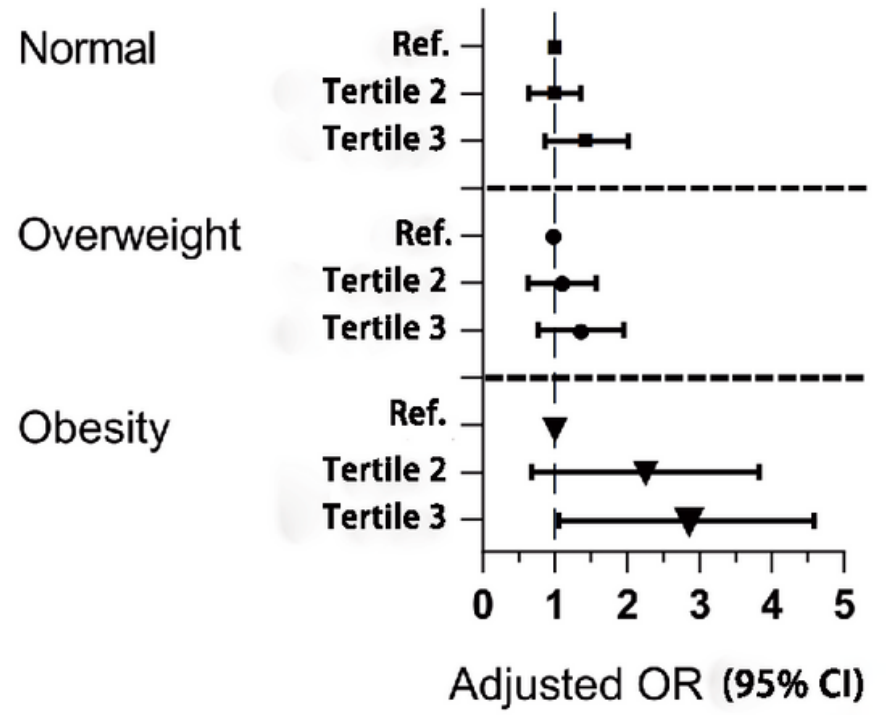

(b)

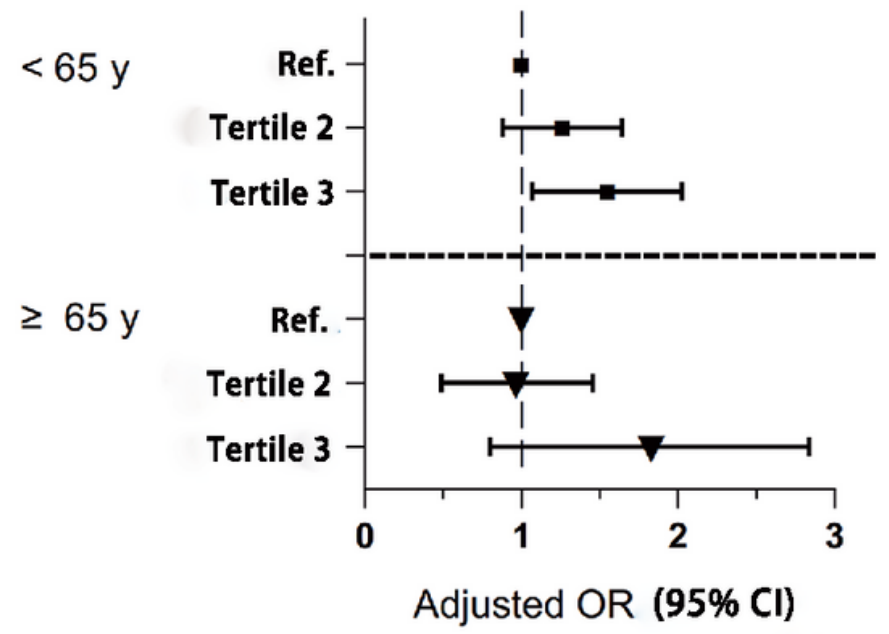

(d)

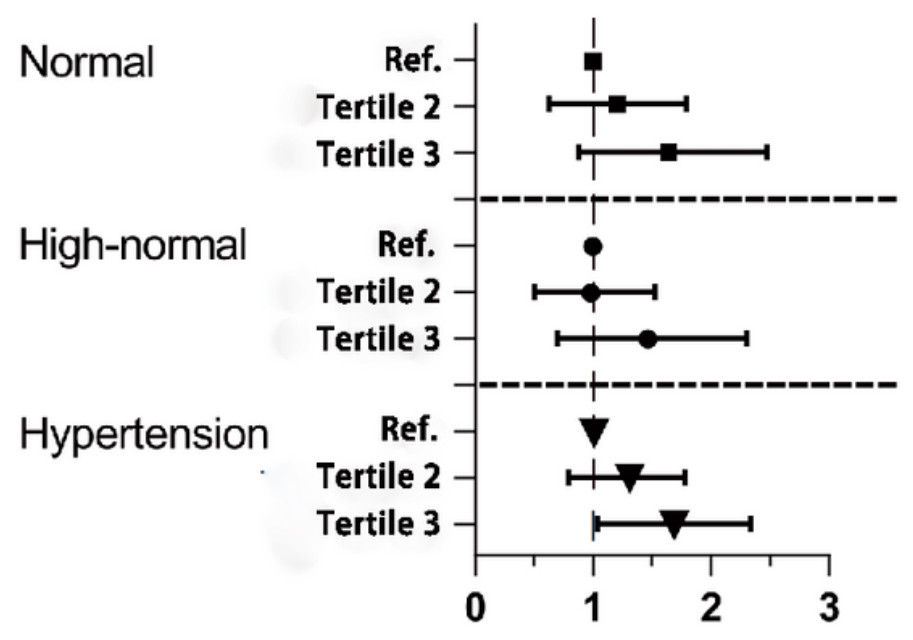

Adjusted OR $(95 \% \mathrm{Cl})$

\section{Figure 3}

presents the results of subgroup analysis showing the relationship between TyG index and CAS. According to gender (Fig. 3a), age (Fig. 3b), blood pressure level (Fig. 3c), and BMI level (Fig. 3d), the population was further divided into groups, and the subgroup analysis was performed. 